\title{
Correspondence
}

\section{Growth hormone treatment increases the predicted adult height}

Sir,

In 1979 Hamilton $^{1}$ suggested that the luteinising hormone that contaminates growth hormone used in this country (hGH(UK)) might lead to accelerated bony maturation and stunting of adult height in treated patients. His paper has stimulated examination of the results of treatment of growth hormone-deficient patients at other centres in the UK. The paper by Milner et al..$^{2}$ in which is analysed the progress of patients, mainly from the Great Ormond Street growth clinic, is reassuring. The results of treatment with hGH (UK) of growth hormone-deficient patients in Newcastle upon Tyne, which were not included in the paper by Milner et al., support their findings.

To assess the effect of growth hormone treatment in patients whose ages and duration of treatment vary greatly we calculated the difference between the predicted adult height at the beginning of treatment and at the present time. The Tanner method of predicting adult height $^{3}$ takes into account not only age and height, but also bone age. As the formula was designed for use in normal children and as the growth velocity of children with growth hormone deficiency is low, the calculation will overestimate the predicted adult height at the start of treatment. Therefore any gain in adult height during treatment indicates a good response to treatment. The results of these calculations in all the growth hormonedeficient patients treated in our clinic since 1967 are shown in the Table.

Idiopathic growth hormone deficiency includes patients with associated gonadotrophin, antidiuretic hormone, and TSH deficiency; partial growth hormone deficiency is defined as a maximum growth hormone level of between 10 and $20 \mathrm{mU} / \mathrm{l}$ during an insulin tolerance test; organic panhypopituitarism includes patients with craniopharyngioma, glioma, astrocytoma, pinealoma, eosinophilic granuloma, and diffuse severe cerebral damage.

The gain in predicted adult height was not related to the growth hormone level during a diagnostic insulin tolerance test nor was it related to height at diagnosis, but it did have a significant negative correlation with age at the start of treatment $(\mathrm{r}=-0.25, \mathrm{P}=0.05)$. All patients who started treatment before age 10 years showed a gain in predicted adult height; the few whose predicted adult height decreased slightly with treatment were all over age 10 years at the start of treatment. These findings confirm the beneficial effect of treatment with hGH (UK) and indicate the importance of early diagnosis and treatment.

\section{References}

1 Hamilton W. What can be expected from growth hormone treatment? (abstract). Arch Dis Child 1979; 54: 971-2.

2 Milner R D G, Preece M A, Tanner J M. Growth in height compared with advancement in skeletal maturity in patients treated with human growth hormone. Arch Dis Child 1980; 55: 461-6.

3 Tanner J M, Whitehouse R H, Marshall W A, Carter B S. Prediction of adult height from height, bone age, and occurrence of menarche, at ages 4 to 16 with allowance for midparent height. Arch Dis Child 1975; 50: 14-26.

\section{J M PARKIN AND P MORRELL Children's Department, Royal Victoria Infirmary, Queen Victoria Road, Newcastle upon Tyne NE1 4LP}

\section{Conservative care of the newborn baby}

Sir,

We do not wish to enter the discussions about the merits of intensive or conservative care of the newborn, or about the criticism of the sampling techniques used by HughesDavies, but to discuss the use of statistics by Pearson. ${ }^{1}$

Pearson correctly emphasises that when considering two small samples, only a large difference between mortality rates would be statistically significant. The $95 \%$ confidence limit for 16 deaths out of 21 subjects in Salisbury is $52.83-91.78 \%$ and for 32 deaths out of 40 subjects in $\mathrm{UCH}$ it is $64.35-90.95 \% \%^{2}$ Pearson accepts this variation for Salisbury but not for UCH when he constructs his hypothetical $2 \times 2$ contingency tables. He

Table Results for growth hormone-deficient patients treated at Newcastle upon Tyne

\begin{tabular}{|c|c|c|c|c|}
\hline \multirow[b]{2}{*}{ Age at start of treatment (years) } & \multicolumn{2}{|c|}{$\begin{array}{l}\text { Idiopathic growth } \\
\text { hormone deficiency } \\
(n=28)\end{array}$} & \multirow{2}{*}{$\begin{array}{l}\begin{array}{l}\text { Partial growth } \\
\text { hormone deficiency } \\
(n=8)\end{array} \\
11 \cdot 4 \\
(7 \cdot 5-16 \cdot 5)\end{array}$} & \multirow{2}{*}{$\begin{array}{l}\begin{array}{l}\text { Organic } \\
\text { panhypopituitarism } \\
(n=19)\end{array} \\
12 \cdot 3 \\
(3 \cdot 1-20 \cdot 2)\end{array}$} \\
\hline & $\begin{array}{l}\text { Mean } \\
\text { Range }\end{array}$ & $\begin{array}{l}11 \cdot 2 \\
(3 \cdot 4-18 \cdot 5)\end{array}$ & & \\
\hline $\begin{array}{l}\text { Height at start of treatment } \\
\text { (SD from mean) }\end{array}$ & $\begin{array}{l}\text { Mean } \\
\text { Range }\end{array}$ & $\begin{array}{l}-4 \cdot 3 \\
(-2 \cdot 8--7 \cdot 5)\end{array}$ & $\begin{array}{l}-3 \cdot 7 \\
(-2 \cdot 4-5 \cdot 0)\end{array}$ & $\begin{array}{l}-3 \cdot 0 \\
(-0 \cdot 3--5 \cdot 0)\end{array}$ \\
\hline Duration of treatment (years) & $\begin{array}{l}\text { Mean } \\
\text { Range }\end{array}$ & $\begin{array}{l}3 \cdot 5 \\
(0 \cdot 5-10 \cdot 1)\end{array}$ & $\begin{array}{l}2 \cdot 3 \\
(0 \cdot 5-9 \cdot 9)\end{array}$ & $\begin{array}{l}2 \cdot 9 \\
(0.5-9 \cdot 0)\end{array}$ \\
\hline $\begin{array}{l}\text { Gain in predicted adult height } \\
\text { (cm) }\end{array}$ & $\begin{array}{l}\text { Mean } \\
\text { SD }\end{array}$ & $\begin{array}{l}+6 \cdot 0 \\
( \pm 5 \cdot 8)\end{array}$ & $\begin{array}{l}+2 \cdot 0 \\
( \pm 2 \cdot 8)\end{array}$ & $\begin{array}{l}+2 \cdot 1 \\
( \pm 9 \cdot 1)\end{array}$ \\
\hline
\end{tabular}


Table Comparison of different possible levels of mortality at $\mathrm{UCH}$ with the observed mortality at Salisbury

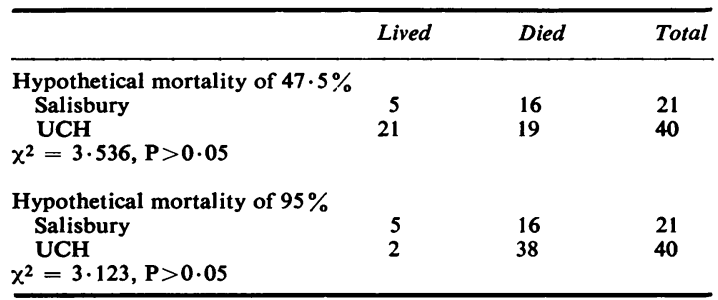

uses the UCH figures as an absolute standard but if the Salisbury figures are held constant (as in our Table) there is no significant difference by the $\chi^{2}$ test using Yates's correction (as Pearson did) between 19 deaths $(47.5 \%$ mortality) and 38 deaths (95\% mortality) at UCH.

No amount of mathematical manipulation will alter the fact that there is no statistically significant difference in mortality between Salisbury and UCH on the quoted figures. We therefore cannot accept Pearson's conclusion that the small size of the Salisbury sample alone makes comparative merits of the methods of care impossible from the data supplied. A controlled trial, preferably one that includes morbidity as well as mortality, is the only way to see which method of care is preferable statistically.

\section{References}

1 Pearson R C A. Conservative care of the newborn baby. Arch Dis Child 1980; 55: 411-2.

2 Diem K, Lentier C, eds. Documenta Geigy scientific tables, seventh edition. Basle: Geigy, 1970: 85-106.

David Burman Bristol Royal Hospital for Sick Children, St Michael's Hill, Bristol BS2 8BJ

AUDREY MORRIS Department of Community Medicine, University of Bristol

\section{Dr Pearson comments:}

The use of the UCH figures as a standard with which to compare the results of neonatal care at Salisbury was not my idea but that of Dr Hughes-Davies. I tried to suggest that this comparison is invalid if such small numbers are involved. Dr Burman and Dr Morris appear to be agreeing with this conclusion. Had the UCH team compared their results with those obtained at Salisbury and drawn conclusions from such a comparison, the approach adopted by Burman and Morris would have shown the inaccuracies inherent in such conclusions in exactly the same way.

R C A Pearson University of Oxford, Department of Human Anatomy, South Parks Road, Oxford $O X 13 Q X$

\section{Allergic bronchopulmonary aspergillosis}

Sir,

Brueton et al. reported the occurrence of 7 cases of allergic bronchopulmonary aspergillosis in patients with cystic fibrosis $(C F)^{1}$ in a short period of time, for which they could find no explanation; they also mentioned that asthmatic symptoms are common in patients with $\mathrm{CF}^{2}{ }^{2}$ When we noted that Aspergillus fumigatus was being isolated more often at this hospital we did not know whether this reflected improved microbiology techniques or a genuine increase. Investigation of possible reasons included an examination of nebulisers, as many patients with CF receive nebulised drugs.

One machine showed a collection of fluff on the air intake grill. Tests showed that the machine discharged large numbers of $\boldsymbol{A}$. fumigatus from the air supply to the nebuliser, and positive cultures for $A$. fumigatus were obtained too from fluff taken from within the casing, the inlet filter, and from both sides of the outlet filter. We feel that the design of this particular machine is unsatisfactory because of the siting of the air inlet.

Brueton et al. commented that the timing of symptoms correlated with seasons previously reported to have a high atmospheric count of aspergilli. The discharge of spores from the nebuliser must be presumed to act in a similar manner. Also, they questioned whether the increased incidence of atopy might reflect some aspect of treatment. We have no evidence that nebulisers initiate allergic bronchopulmonary aspergillosis but they must exacerbate the problem. Our machine was one of 2 machines used by inpatients with CF. Although we examined the second machine, and a number of others of different designs, we did not find $A$. fumigatus. However, it was noticed that the nebuliser into which the drug is placed is sometimes inadequately cleaned in machines used in the home. It is possible that aspergilli, and perhaps certain bacteria, are unwittingly being nebulised into patients. We feel that further studies are needed to determine the extent of this problem.

\section{References}

1 Brueton M J, Ormerod L P, Shah K J, Anderson C M. Allergic bronchopulmonary aspergillosis complicating cystic fibrosis in childhood. Arch Dis Child 1980; 55: 348-53.

2 Warner J O, Taylor B W, Norman A P, Soothill J F. Association of cystic fibrosis with allergy. Arch Dis Child 1976; 51 : 507-11.

R H George and A P Gillett Department of Microbiology, Birmingham Children's Hospital, Birmingham B16 8ET

Professor Anderson comments:

I thank Dr George and Dr Gillett for their letter on their findings concerning inhalation machines and the presence of Aspergillus fumigatus; we asked them to make such a 